\title{
ROMA HUKUKU'NDA EKSIKK BORÇ (OBLIGATIO NATURALIS) OLARAK DOĞAN BORÇLAR
}

\author{
Dr. Haluk EMIROĞLU*
}

\section{GÍRIŞ}

Roma hukukunda, hak (ius) ile dava (actio) kavrambarı arasında yakın bir ilişki vardı. Çünkï hak, özellikle kişiye karşı kullanıldığında, hak sahibinin bu hakkını bir başka kişiye karşı ileri sürmesi durumunda açıkça ortaya çıkardı. Romalılar, hak sahibinden, actio'su (dava hakkı) olan kişi olarak söz ederlerdi. Cumhuriyet Dönemi hukukçularından Celsus, actio'yu, hukuken ifa edilmesi gereken edimin, mahkemeler önünde takip hakkı olarak tanımlamıştı. Aynı tanım, daha sonra Iustinianus'un Institutiones' inde de yerini almıştı. ${ }^{1}$ Roma hukukunda, bütün hakların mahkemeler önünde ileri sürüllebilmesini sağlayan genel bir dava öngörülmedił̌ için, hak ile dava arasındaki ilişki, günümüz hukukuna göre çok daha sıkıydı. Hukuken korunmaya değer görülen her menfaat için, ayrı bir davanın tanınmış olması gerekliydi. Bu nedenle, Roma hukukunda, hukuken takip edilmesi, yargı organları önünde ileri sürülebilmesi ve koğuşturulabilmesi için özel bir dava öngörülmemiş olan bir hak söz konusu olamazdı. Bu durum, Romalıların, hakları, bu haklari elde etmeye yarayan actio'lar bakımindan sınflandırmalarına yol açtığından, Roma özel hukuku, bir actio'lar sistemi üzerine kurulmuştu. Nitekim, praetor'ların Roma özel hukukuna en önemli katkıları da, toplumsal, ekonomik ve siyasal koşulların değişmesi sonucu

\footnotetext{
'Ankara Üniversitesi Hukuk Fakültesi Roma Hukuku Anabilim Dalı Araştırma Görevlisi.

${ }^{1}$ D. 44. 7.51 (CELSUS libro tertio digestorum): 'Nihil aluid est actio quam ius quod sibi debeatur, indicio persequendi.'

D. 44. 7. 51: 'Dava, hakkın sahibi tarafından, mahkemeler önünde ileri sürüłmesinden başka bir şey değildir.'

Its. Ins. 4. 6. pr: 'Superest, ut de actionibus loquamur. Actio autem nihil aluid est, quam ius persequendi iudicio quod sibi debetur.'

Ius. Ins. 4. 6. pr: 'Nihayet, davalardan söz etmek gerekiyor. Dava, borçlu olunan şeyi, mahkeme önünde talep etme hakkından başka bir şey değildir.'
} 
ortaya çıkan yeni menfaatlerin korunması için, yeni dava hakları tanımak olmuştu. ${ }^{2}$

Roma hukukunda, hukuki sonuçları bakımından borçlar, obligatio civilis (tam borç) ve obligatio naturalis (eksik borç) olmak ùzere ikiye ayrılırdı. Alacaklının, kendisine tanınan dava ile, gereğinde icra yoluna da başvurarak, cebren hakkını elde edebildiği borçlar, obligatio civilis'ti. Bununla birlikte, günümüz hukukunda oldugu gibi, Roma hukukunda da eksik borçlar, hukuk düzeni tarafıntan öngörülmüştü. Bu durumda, Roma hukuku, bir kimsenin borçlu olduğunu kabul etmekle birlikte. o kimseye karşı bir dava ve icra olanağı sağlamamıştı. Romalılar, ifası actio ile takip edilemeyen bu davasız borçları, obligatio naturalis (eksik borç) ismi altında toplamışlard1. ${ }^{3}$ Obligatio naturalis, dava hakkı olmamakla birlikte, başta soluti retentio (ödenen şeyin muhafazası) ${ }^{4}$, yani borçlu tarafından alacaklıya yapılan ödemenin (solutio debiti) geçerli olarak kabul edilmesi ve ödenenin, condictio indebiti (sebepsiz zenginleşme davası) ile geri alınamaması hakkını veren, ayrıca, kefalet, rehin veya ipotek yoluyla, geçerli olarak şahsi ya da ayni teminat altına alınabilen ve novatio ile yenilenebilen bir borçtu. ${ }^{5}$ Roma hukukunda bazı borçlar, doğumları anından itibaren obligatio naturalis oldukları halde, bazı borçlar, obligatio civilis olarak doğmalarına rağmen, daha sonra obligatio naturalis niteliğini kazanırdı. Kölelerin borçları, ayn aile iyelerinin birbirlerine karşı borçlanı ve Senatus Consultum Macedonianum'a aykırı olarak aile evlatlarına verilen ödünçler, doğumlarından itibaren eksik borç olarak nitelendirilen borçlardand.."

\section{KÖLELERIN BORÇLARI}

Roma hukukunun bilgi kaynakları incelendiğinde, obligatio civilis ve obligatio naturalis ayrımının ilk kez Klasik Hukuk Dönemi'nde, kölelerin borçlarının hukuki niteliğinin belirlenebilmesi amacıyla yapıldığı görüliur.?

\footnotetext{
'KARADENIZ-ÇELEBICAN, Ö.: Roma Hukuku (Roma), Ankara 2000. s.l18-119.

${ }^{3}$ D. 12.6.51 (POMPONIUS libro sexto ad Quintum Mucium): 'Ex quibus causis retentionem quidem habemus, petitionem autem non habemus, ea, si solverimus repetere non possumius.'

D. 12. 6. 51: 'Muhafaza etme hakkımız bulunan, ancak, dava açarak takip etme hakkınuz olmayan şeyleri ifa edersek. o şeylerin iadesini isteyemeyiz.'

${ }^{4} \mathrm{Bkz}, \mathrm{dn} .30$.

${ }^{5}$ Dl MARZO. S. (Çev.: UMUR, Z.): Roma Hukuku, İstanbul 1954, s.353; RADO, T.: Roma Hukuku Dersleri. Borçlar Hukuku (Borçlar), Istanbul 1978, s.25; TAHIROĞLU. B.: Roma Borçlar Hukuku, İstanbul 2000, s.30.

' ZIMMERMANN, R.: The Law of Obligations. Cape Town 1992. s.7: BERKİ, Ş.: Roma Hukuku, Ankara 1949, s.318.

${ }^{7} G$ Gi. Ins. 3.119 a: 'Fideiussor vero omnibus obligationibus, id est sive verbis sive titteris sive consensu contractae fuerint obligationes, adici potest at ne illud quidem interest. utrum
} 
Çünkü, Roma ailesi (familia) içinde, özgür olmayan ve Roma yurttaşı sayılmayan köleler, res mancipi grubuna giren bir mal olarak alınıp satılıyorlar, borç ilişkilerinin konusunu oluşturabiliyorlardı. Ancak kölelerin, düşïnen ve irade sahibi canlı varlıklar olması, onların işledikleri haksız fiiller dolayısıyla ortaya çıkan sorumluluklarının dışında, başkalarıyla hukuki ilişkilere girişmelerini de kaçınılmaz kılıyordu. Bu nedenle, ortaya çıkan hukuki anlaşmazlıkların çözülebilmesi için, 'Kölelerin yaptıkları hukuki işlemler nedeniyle kazandıkları haklar, doğrudan doğruya onlar üzerinde dominicia potestas (köle üzerindeki egemenlik) sahibi olan efendilerine ait sayılırken ${ }^{8}$, yüklendikleri borçlardan efendileri sorumlu tutulamaz' kuralı kabul edilmişti. ${ }^{9}$ Kölenin yaptığı hukuki işlem sonucunda, efendi ya da azat edildikten sonra köle, aslında hukuken ödemek zorunda olmadığ bu borcu öderse (causa solvendi), yapılan ödeme bir condictio indebiti (sebepsiz zenginleşme davası) ile geri istenemezdi. Eksik borçların ifasinın, varolmayan bir borcun ifası (indebitum solutum) olmaması sebebiyle, sebepsiz zenginleşme meydana getirmeyeceği Digesta'da açıkça belirtilmişti. ${ }^{10} \mathrm{Bu}$ durumda, Ius Civile tarafindan kendisine aktif ve pasif

civilis an naturalis obligatio sit, chi addiciatur; adeo quidam, ut pro servo quoque obligetur, sive extraneus sit, qui a servo fideiussorem accipiat, sive ipse dominus in id, quod sibi debeatur.'

Gai. Ins. 3. 119 a: 'Kefalet, ister ayni, ister sözlì. jster yazılt, ister nzai, her tïrlü borç için söz konusu olabilir. Hatta, yüklendiği borcun tam ya da eksik borç olmasının da hiçbir önemi yoktur; bir kimse, kölenin borçlu oldułu bir yabancıya veya kölenin malikine karşı bile kefrt] olabilir."

Lus. Ins. 3. 20. 1: 'In onnibus autem obligationibus adsumipossunt, id est sive re sive verbis sive litteris sive consensu contractae fuerint: Ac ne illud quidem interest, utrum civilis an naturalis sit obligatio, cui adiciatur fideiussor, adeo quidem, ut pro servo quoque obligetur, sive exfraneus sit qui fideiussorem a servo accipiat, sive ipse dominus in id quod sibi naturaliter debetur.'

lus. Ins. 3. 20. 1: 'Kefalet, ister ayni, ister sözlü. jster yaztl, ister ruzai sözleşmelerle meydana gelen bütün borç ilişkileri için söz konusudur. Borcun, tam ya da eksik olması da önemlj değildjr.; hatta, bir kimse, bir köle için bile, gerek bir yabancıya karşı, gerekse bizzat malike karşı, o kölenin bağlı bulunduğu eksik borç ilişkisinin kefili olabilir.'

${ }^{8}$ Gai. Ins. 1. 52: 'Quod cumque per servum adquiritur, id domino adquiritur.'

Ga.Ins. 1. 52: 'Kölenin kazandı̋̆ı her şey, efendj için kazanılmıştır.'

${ }^{9}$ KARADENIZ, Ö.: Roma Hukukunda Peculium Müessesesi (Peculium), AOHFD 1968 , C. XXV, S. 3-4, s.180-181; ZIMMERMANN, s.52; TAHIROĞLU, s.30.

${ }^{10}$ D. 12. 6. 13 (PAULUS libro decimo ad Sabinum): 'Naturaliter etian servus obligatur: et ideo, si quis nomine eius soluat vel ipse manumissus, ut Pomponius scribit, ex peculio cuilus liberam administrationem habeat, repeti non poterit: et ob id et fideiussor pro servo acceptus tenetur et pignus pro eo datum tenebiur.'

D. 12, 6. 13: 'Köle, eksik borçla borçlanabilir: bu nedenle, bir kimse onun hesabına ödemede bulunursa ya da Pomponius'un yazdığ gibi, kendiși azat edildikten sonra. kendisinin yönetimine bırakılan peculium'dan bu borcu öderse, geri istenemez. Bu da gösterir ki, bir köle için kabul edilen kefil ya da kölenín borcu jçin verilen rehin geçerlidir.' 
dava ehliyeti de tanınmayan köle, hukuki işlem yaptığı kimseye karşı obligatio naturalis ile yükümlü sayılırdı. ${ }^{11}$

Önceleri tarıma dayanan Roma toplumu, ticarete dayanan ekonomiye geçmeye başlayınca, Roma hukukunda doğrudan temsil kurumu kabul edilmediği için, efendi ya da aile babasının, bu ilişkileri tek başına yürütmesinin pratik olarak güçleştiği görüldü. Bu duruma, aile babasınm ekonomik olanaklarını, aile evlatlarının ve kölelerinin faaliyeti ile genişletmek isteği de eklenince, aile babaları, aile evlatlarına ve kölelerine, aile malvarlı̆̆ın belli bir bölümï ỉzerinde sınırlı bir yetki tanımaya başladılar (peculium). Praetor'da bu yetki dolayısıyla, aile babasma ya da efendiye karş1, actio adiecticiae qualitatis (ek nitelikte dava) açma olanağı vererek, onun, peculium'un o andaki değeri kadar sorumlu tutulmasını (miktar bakımından sınırı sorumluluk) sağlayınca, peculium, köleler ve aile evlatları için uygulanabilen bir hukuki kurum olarak ortaya çıtı. ${ }^{22} \mathrm{Bu}$ durumda kusal olarak, köle, bir hukuki işlem yaparsa, doğrudan doğruya kendisi borç altına girerdi; fakat bu borç, obligatio naturalis'ti. Ancak, kendisine peculium verilen kölenin efendisine, peculium 'un o anki değeri ile sınırlı olmak üzere dava açmak mümkündü. Peculium'un değerinin üstündeki miktar için ise, kölenin obligatio naturalis olarak borcu devam ederdi. ${ }^{1.3}$ Obligatio naturalis olarak nitelenen borç, köle tarafından (azat edildikten sonra) ya da üçüncü kişiler tarafından, geçerli bir şekilde ifa edilebilirdi; alacaklının, köleye karşı azat edildikten sonra bile bir dava açma olanağı yoktu. ${ }^{14}$ Peculium, köle ya da aile evlatları ile hukuki ilişki kuran kişilere, alacaklarını elde edebilmeleri konusunda güvence getirerek, köle ya da aile evlatlarının, ticari yaşama katılmalarını sağlayan bir kurumdu. Eğer bir kişi, peculium sebebiyle borçlu bulunduğu bir köle ya da aile evladına verilmiş olan peculium'un ortadan kalktığmı bilmeyerek ifada bulunursa, borcundan kurtulurdu. Ancak, aile evladının peculium'unun bulunmadığını bilerek yapılan ifa sonucunda, varolmayan bir borç ödendiği için, iade talebi de söz konusu olamazdi..$^{15}$

" D. 50. 17. 107 (GAIUS hibro prime ad edictum prouinciale): 'Cum servo nullu actio est."

D. 50, 17. 107: 'Köleye karşı hiçbir dava yoktur.'

D. 2. 11. 13 (IULIANUS libro quinquagensimo quinto digestorum): 'Quia servis conueniri vel contutite non potest.'

D. 2. I1 . 13: 'Köle, davacı ya da davalı olamaz.'

'2 KARADENİZ (Peculium), s.181-182.

${ }^{13}$ RADO (Borçlar), s.26.

${ }^{14} \mathrm{Bkz}$. din. 7-8,

is D. 12, 6. 26, 8 (ULPIANUS fibro vicensimo sexto ad edicrum): 'Qui filio familias solverit, cum esset eius peculiaris debitor, si quidem ignoravit ademptum ei peculitm. liberatur: si scit et solvit, condictionem non habet, quia sciens indebitum solvit." 


\section{AİLE (FAMILIA) ÜYELERİNIN BÍRBÍRLERİNE KARŞI BORÇLARI}

Roma ailesinde, aile evlatları da hak ehliyetleri bulunmadığı için, hak sahibi olamazlar ve borçlarından sorumlu tutulamazlardi. Bu nedenle, aile evlatlarının, inter vivos (yaşayanlar arasında) ya da mortis causa (ölüm sebebiyle) kazandıkları bütün haklar, aile içinde hak ehliyeti sahibi tek kişi olan, aile babasına ait olurdu. ${ }^{16}$ Buna karşllık, tıpkı kölelerde oldugu gibi, aile evlatlarmın hukuki işlemler sonucunda yüklendikleri borçlar, aile babası bakımından hiçbir hukuki sonuç doğurmazdı. Ancak, aile evlatları, kölelerden farklı olarak, yaptıkları hukuki işlemler dolayısıyla bizzat borçlanıyorlardı. Bu borçlar, kölelerin borcu gibi, obligatio naturalis değil, obligatio civilis'ti. Yani, aile evlatlarına karşı, bu borçlardan dolayı, Klasik Hukuk Dönemi'nden itibaren dava açllabiliyordu. Pasif dava ehliyeti bulunan aile evlatlarının, aktif dava ehliyeti yoktu. Ancak, hak ehliyetinden yoksun olan aile evlatlarmın, bu nedenle, malvarlığına sahip olmaları da mümkün olmadığından, kendilerine karşı açılan davaların, alacakłılara pratik açıdan bir şey kazandırma olanağı yoktu. Peculium bakımından ise, kölelere uygulanan kurallar, bïyiik ölçüde aile evlatlarına da uygulanıyordu. Peculium smırı içinde kalan borçlardan, aile babasının da sorumluluğu kabul edilmekle birlikte, diğer borçlardan, sadece aile evlad1, obligatio civilis ile sorumlu olurdu. Iustinianus Dönemi nde, peculium kurumunun gelişimi ve yaygınlaşması sonucunda, aile evlatlarına da hak ehliyeti verilince, alacaklıların, doğrudan doğruya aile evladının malvarlığından alacaklarını elde etmesi de mümkün oldu. ${ }^{17}$

Roma hukukunda, aynı familia'nın ïyeleri arasında yapılan hukuki işlemlerden ise, malvarlığının sadece aile babasına ait olması nedeniyle, obligatio naturalis dogardı. Bu durumda, aile babası (pater familias) ile aile evlatları arasında ya da aynı baba egemenliği altında bulunan iki aile evladı arasındaki borçlar, obligatio naturalis olarak nitelendirilmişti. ${ }^{18}$

D. 12, 6. 26, 8: 'Eğer bir kişi, peculium'u sebebiyle borçlu olduğu baba egemenliği a)tındaki ajle evladına, peculium'un ortadan kalktığını bilmeden, ifada bulunmuşsa, borcundan kurtulur. Ancak bu kişi, durumu bilerek ödeme yaptıysa, kendisine condictio verilmez. Çünkủ bu kişi, sahip olmadığı bir borcu bilerek ödemiş sayılır.'

${ }^{16}$ SCHULZ. F. (Çev.: KARAGÖZ, H.): Auctoritas, İÜHFM 1997, C. LV, S. 4, s.342; ZIMMERMANN, s.52.

${ }^{17}$ KARADENIZ (Roma), s.170-171; RADO (Borçlar), s.26; ZIMMERMANN, s.52.

${ }^{18}$ D. 12. 6. 38 (AFRICANUS libro nono quaestionum): 'Frater a fratre, cum in eiusdem potestate essent, pecuniam nutuatus post mortem patris ei soluif: quaesitum est, an repetere possit. respondit utique quidem pro ea parte, qua ipse patri heres exstitisset, repetiturum pro ea uero, qua frater heres extiterit, ita repetiturum, si non minus ex peculio suo ad fratrem peruenisset: naturalem enim obligationem quae fuissef hoc ipso sublatam uideri. quod peculii 


\section{SENATUS CONSULTUM MACEDONIANUM'A AYKIRI OLARAK AİlE EVLATLARINA VERILEN PARA ÖDÜNÇLERİ}

Senatus Consultum Macedonianum, Roma'da İlk İmparatorluk (Principatus) Dönemi'nde, birinci yüzyılda yapılmış olan ve aile evlatlarına ödïnç para verilmesini yasaklayan, verilmesi durumunda ise, aile evlatlarını bu borcu ödeme zorunluluğundan kurtaran ve Corpus Iuris Civilis aracıllğ 1 ile öğrendiğimiz bir senatus karandır. ${ }^{19}$ Digesta'da Ulpianus tarafından söz edilen senatus kararında, aile evlatlarına ödünç para veren kimselere, aile evladının egemenliği altında bulunduğu aile babası ölse de, dava açma hakkı tanımamışt. ${ }^{20}$ Sadece, aile evladına ödünç veren kimsenin değil, onun mirasçılarının da dava açma hakkı yoktu." Senatus Consultum Macedonianum tarafından korunan aile babası ile baba ve büyük babaya karşı, alacaklının açtığı davanın kabul edilmeyece ğine ilişkin kural, Iustinianus Institutiones'te ayruntıly olarak düzenlenmişti. ${ }^{22}$

partem frater sit consecutus, adeo ut, si praelegatum filio eidemque debitori id fuisset. deductio huius debiti a fratre ex eo fieret.

D. 12.6.38: 'Bir aile evlad, aynı baba egemenliği altında bulunan diğer bir aile cvladına ödünç para verse ve aile babaları öldükten sonra, borcunu geri ödese, ödediğini geri alabilirmi? Julianus'a göre, borçlu olan ve şu anda ödedigini geri almak isteyen aile cvladı. ödediği miktarı, her durumda aile babasının terekesinden, kendisine düşen mirass payından alabilir.* Diğer aile evladına düşen miras payına ise, borçiu aile evladına tahsis edilen peculium'un borç miktarından fazla olması durumunda başvurabił̧r. Bu da, ödünç tutarından kalan kısmı tam olarak karşılar,*** Böylece, tarafłar arasında geçerli olan eksik borç. mirás payı jłe birlikte peculium' un da bir bölíimüne başvurulması sonucunda ödenmiş olur.

*Bu durunda eksik borç, alacaklı ve bơçlu sıfatlannın birleşmesiyle ortadan kalkardı.

*Aksi durumda. ödünç tutarı iki kez elde edilmiş olabilirdi. Bkz. D. 12. 1. 38.

${ }^{19}$ Ayrıntılı bilgi için bkz. RADO, T.: Senatus Consultum Macedonianum ve Roma Hukuku'nda Fitius Familias'ların Para Ödünçleri (Senatus), Yayınlanmamış Doçentlik Tezi. Istanbul 1944.

${ }^{21} D .14 .6$. I (ULPIANUS libro vicensimo nono ad edictum): 'Placere, ne cui, qui filio familias munum pecuniam dedisset, etiam post mortem parentis eius, cuius in potestatefuisset, actio petitioque daretur, ut scirent, qui pessimo exemplo facterarent, nullius posse flii familias bonum nomen expectata patris morte fieri.'

D. 14. 6. 1: 'Senatus'un kararına göre, ajle evladına ödünç veren kimseyc. o aile cvbadının egemenliğ altında bulunduğu aile babası ölse biłe, bit actio ya da bir petitio verilmemeliclir. Çünkü, ödünç para vererek başkalarına kötï örnek olanların, aile babasının ölümünü beklemekle. fitius familias'a karşı alacaklarınm durumunun düzelmeyeceğini bilmeleri gerekir.'

${ }^{21}$ D. 14, 6. 7. 6 (ULPIANUS Iibro vicesimo nono ad edictum): 'Non solum ei, qui mutuam dedisset, sed et successoribus eitus deneganda est actio.'

D. 14. 6. 7. 6: 'Sadece, ödünç verenin davası değil, onun mirasçılanının davası da kabıl edilmez.'

${ }^{22}$ Ius. Ins. 4. 7. 7: 'Mlud proprie srevatur in eorum persona, quod Senutis Consulium Macedonianum prohibuit mutuas pecunias dari eis, qui in parentis erum potestate: et a qui crediderit denegatur actio tam adversus ipsum filium filiamve, nepotem neptemve. sive adhuc 
Aile evlatlarına ödünç para verilmesini yasaklayan senatus kararı, aynı zamanda onlara, bir defi (exceptio) ileri sürme olanağı da tanımıştı. Ancak, bu defi, borçluyu korumak amacıyla değil, alacaklıya ceza olarak öngörüildüğ $\mathrm{i}$ (ob poenam creditoris) için, soluti retentio kabul edilerek, borçlunun yapmış olduğu ifayı geri alması engellendiğinden, hukuken bir eksik borç meydana gelirdi. Bu durumda, aile evladı, aldığı ödüncü, aile babasının ölümünden sonra öderse, ödediğini bir condictio ile geri isteyemezdi. ${ }^{23}$ Aile babasının aile evladına, Roma ya da uzak bir yere giderken, zorunlu harcamalarını yapması için verdið̧i para ödünçleri, bu senatus kararının içinde değerlendirilmezdi. ${ }^{24}$

Senatus Consultum Macedonianum'a göre, aile evladının aldığı ödünçten doğan borç ödendiğinde, ortada bir eksik borç olduğundan, ödenen, condictio indebiti ile geri istenemezdi. ${ }^{25}$ Ancak aile evladı, aile babası egemenliği altındayken aldığ borcu, yine aynı aile babasının egemenliği altındayken öderse, farklı bir hukuki durum ile karşılaşılırdı. Aile babası egemenliği altında bulunan aile evladının kendisine ait malvarlığı bulunmadığından, aile evladı tarafından ödenen borç, aslında aile babasının mal varlığından çıktığından, verilen paraların mülkiyeti, alacaklıya geçmezdi

in potestate sum, sive morte parentis vel emancipatione suae potestatis esse coeperint, quam adlersus patrem avumve, sive habeat eos adhuc in potestate sive emancipaverit. Quae ideo Senatus prospexit quia saepe onerati aere alieno creditarum pecuniarum. quas in Luxuriam consumebant, vitae parentium insidiabantur.'

Ius. Ins. 4. 7. 7: 'Baba egemenliği altında bulunan ve Senatus Consultum Macedianum tarafından kendilerine para ödüncú verilmesi yasaklanan kimseler için, şu ozzel hüküm dikkate alınır: böyle bir kimseye ödünç vermiş olana ister egemenlik altında olsunlar, ister babanın ölümü ya da emancipatio ile egemenlikıen çıkmış olsunlar, kız, erkek aile evladı ya da torununa karşı dava açma hakkı verilmediği gibi; aile evlatlarını egemenliği altında bulundursa ya da egemenlikten çıkarsa bile, aile babasına ya da büyük babaya karşı da dava açma hakkı verilmez. Aile evlatlan, bir çok kez başkaiarından aldıkları ödünç paralan boş yere israf ettikten sonra, yỉklendikleri borçiar nedeniyle, aile babalarının yaşamlann tehdit ettikleri için bu Senatus kararı alınmıştur.'

${ }^{3}$ D. 12.6. 40 (MARCIANUS libro tertio regularum): 'Qui exceptionem perpefuam habet, solutum per errorem repetere potest: sed hoc non est perpetutum. nam si quidem eius causa exceptio datur, cum quo agitur, solutum repetere potest, ut accidit in senatus consulto de intercessionibus: ubi vero in odium eius cui debetur exceptio datur, perperam solutum non repesitur, veluti si filius familias, contra Macedonianum mutuam pecuniam acceperit et pater familias factus solverit, non repetit.'

D. 12. 6. 40: 'Sürekli defiye sahip olanlar, hata sonucu ödediklerini geri isteyebilirler. Eğer bu defi. hakkında dava açılan kimse için tanınmışsa, ödediğini geri alabilir. Ancak, defi. alacaklı aleyhine tanınmışsa, borçlu, düşüncesizce yapmış olduğu ödemeyi geri isteyemez. Senaus Consultum Macedonianum hükümlerine rağmen ơđünç para alan aile evladı, aile babası olduğu zaman borcu ơderse, ödediłini geri alamaz.'

${ }^{24}$ DI MARZO, s. 355.

${ }^{25}$ D. 14. 6. 10 (PAULUS libro trigensimo ad edictum): 'Quia naturalis obligatio manet.'

D. 14. 6. 10: 'Çünkü, ortada bir eksik borç vardır.' 
ve aile babası, ona karşı istihkak davası (rei vindicatio) açabilirdi. ${ }^{20}$ Bununla birlikte, senatus kararma aykırı olarak borcu odeyen aile evladı, aile babası öldükten sonra ve onun mirasçısı sıfatıyla ödediği paraları talep ederse, bu talebine karşllık bir defi (exceptio doli generalis) ileri sürülebilirdi. ${ }^{77}$ Aile evladının ödünç aldığı paraları, aile babası yaşarken üu̧üncü bir kişiden bă̆ış alarak, ödemesi durumunda ise, ik.i durumu birbirinden ayırmak gerekirdi. Iulianus'a göre, bağış yapan, borcunu ödemesi şartıyla aile evladına para vermişse, borç, bağı ıs yapan tarafından ödenmiş sayılırdı. Bağış, şartsız olarak yapılmışsa, bağış konusu, aile babasının mal varlığına gireceğinden, aile babası, bu paraları geri isteyebilirdi. ${ }^{29}$

\section{SONUÇ}

Roma hukukunda, eksik borçlarmn bir üst kavramını ifade eden soluti retentio, kendisine karşı açılabilecek bir dava hakkı öngörülmemekle birlikte, borçlunun, yapmış olduğu ifayı geri alamaması anlamına gelirdi. Eğer bu borçlar ödenirse, borç olmayan şeyin ifası sôz konusu olmadığından, alacaklı, aldı ̆̆ını muhafaza edebilirdi. ${ }^{30}$

${ }^{5} D .12 .1 .14$ (ULPIANUS libro vicensimo nono ad edictum): 'Si filius familias contra senatus consultum mutaatus pecuniam solverit, patri numnos vindicami mulla excepto obicient.

D. 12. I. 14: 'Eğer aile evladı, senatus consuttum'a aykırı olarak ödünç aldığ parayı gcri öderse, aile babasının ödenen paraları istihkak talebine karşı herhangi bir defi ileri sürülemez,'

${ }^{27}$ D. 12 . 6. 26.9 (ULPIANUS tibro vicensimo sexto ad edictum): 'Filitis familias contrat Macedoniamm mutuatus si solverit et patri sto herres effectus, velit vindicare nummos. exceptione stmmo vebitu a vindicatione nummorum'

D. 12. 6. 26. 9: 'Senatus Consultum Macedoniamum'a aykırı olarak, aldığı ödüncü ödeyen aile evladı. aile babasınıı mirasçısı oldığu zaman, bu paralan geri almak istersc. istihkatk iddiasına karşıı, bir đlefï ileri sürülebilir.'

${ }^{2 x}$ D. 14. 6.9. I (ULPIANUS hibro vicensimo nono ad edictum): 'Si ab alio donatam sibi pecuniam filins creditori solverit, an pater vindicare vel repetere possit? et sit hilimus, si quidem hac conditione ei donata sit pecunia, ut creditori solvat, videri a donatore profertam protinus ad creditorem et fieri numbos accipientis: si vero simpliciter ei donarit. alienationem corum filium non habuisse et ideo, si solverit, condictionem parri ex omni eventu competere.

D. 14. 6. 9. l: 'Başkası tarafından kendisine bağışlanan para ile ailc evladı borcunu ödemişse, aile babası bu paranıngeri veriłmesini isteyebilirmi? Muliants' a görc, parayı bağışlayan, bunu borcun ödenmesi şartıyla vermişse, borcu kendisi ödemiş sayılır ve paralar iktisap edenin olur; fakat paralar şartsız olarak bağışłanmışa, aile cvladı, borcu ôdemesi durumunda, bunların mülkiyetini karşı tarafa geçirememiş olduğundan. aile babası bunları bir condictio ile talep edebilir.'

${ }^{x y}$ RADO (Senatus). s.136-140.

"UMUR, Z.: Roma Hukuku Lügatı, Istanbul 1983, s.200. 
Roma hukukunun bilgi kaynakları incelendiğinde, eksik borç kavramının sistematik olarak đüzenlenemediği görü̈lür. Eksik borç olarak ifade edilen çeşitli borçların hükümleri, ayrıntıları tamamen birbirinden farklıydı. Bununla birlikte, bu borç ilişkilerinin ortak yanı, bir actio ile korunmamıs olmalarında, yani borçluyu zorlama imkanının tanınmamasında, borçlunun rızası ile ödenmesi durumunda da alacaklının ödeneni muhafaza etmesinde, kefalet ya da rehin yoluyla teminat altma alınabilmelerinde ve yenileme (novatıo) yoluyla da geçerli bir borç durumuna getirilebilmelerinde gözükürdü. ${ }^{31}$

Roma hukukunda, pratik örneklerden yola çıkılarak düzenlenen eksik borç kavramı, borcun doğumu anında eksik borç olması ya da tam borç olarak doğmasına rağmen, daha sonra eksik borç niteliğini kazanması bakımından ise sınıflandırılabilir. Eksik borç olarak doğan borçların en önemlileri, kölelerin borçları, aile üyelerinin birbirlerine karşı borçlanı ve Senatus Consultum Macedonianum'a aykırı olarak aile evlatlarma verilen ödünçlerdi. Daha sonra eksik borç niteliği kazanan borçların en önemlilerinin ise, litis contestatio (davanm tespiti) ${ }^{32}$ ve capitis deminutio (hak ehliyetinin ortadan kalkması) ile sona eren borçlar olduğu söylenebilir. ${ }^{33}$

Davanm tespiti anlamina gelen litis contestatio'nun, usul hukuku bakımından borcu sona erdiren sebeplerden biri olduğu, Gaius tarafindan ifade edilmişti ${ }^{34}$ Bir uyuşmazlık, litis contestatio aşamasına geçince, davaya neden olan borç ilişkisi, artık bir 'usul hukuku ilişkisì' durumuna gelirdi. Böylece, asıl borç ilişkisi sona ererek, onun yerini hakimin kararma uyma yükümlülüğü aldığından, litis contestatio işlemi, borcun yenilenmesi (novatio) niteliği taşırdı. Ancak litis contestatio, novatio'dan farklı olarak, borcun teminatlarını ortadan kaldırmadığından, borç için verilen teminatlar ile birlikte, faizler de işlemeye devam ederdi. ${ }^{35} \mathrm{Bu}$ durumda, kanun

${ }^{31}$ RADO (Borçlar), s.27; TAHIROĞLU, s 30

${ }^{32}$ Özel Muhakemeler Düzenlemesinde (Ordo Oudiciorum Privatorum) litis contestatio ile birlikte magistra önündeki aşama biter ve hakim önündeki aşama başlard. Davacının praetor'dan aldığ formula'yı davalıya tebliğ etmesi ve davalının formula'nın kapsamını kabul etmesinden ibaretti. Bu anda, önceki mevcut borç sona ererdi. Bkz. TAHİROĞLU, s. 78 .

${ }^{33}$ ZIMMERMANN, s.7; BERKI, s. 318.

${ }^{34}$ Gai. Ins. 3. 180: 'Tollitur adhac obligatio litis contestatione, si modo legitimo indicio fuerit actum. nam tunc obligatio quidem principalis dissoluitur, incipit autem teneri reus litis contestatione'

Gai. Ins. 3. 180: 'Boŗ̧ ilișkisi, bir indicium legitimum* açılmış ise, litis contestatio ile sona erer; bu andan ițbaren esas borç ortadan kalkar ve davalı bundan sonra, litis contestatio'dan sorumiu olmaya başlar.'

*Kanuni yargılama usulü, bunun aksi iudicium imperio continens'ti. Bkz. Gai. Ins. 4. 103.

${ }^{35}$ TAHİROĞLU, s.79; RADO (Borçlar), s.235. 
tarafından değil de, aslında tarafların iradesi ile ortadan kalkan borcun yerine, kanun tarafından, novatio ile yeni bir borcun yaratılmasının öngörülmesi sonucunda, eski borç, eksik borç niteliği kazanurdı. Ihstinianus Dönemi'nde formula usulü kalkmış olduğu için, bu dönemde, borçların sonà erme sebepleri arasında litis contestatio yer almadığından, sonradan bu eksik borcun yaratılması olanağı da ortadian kalkmıştı.

Roma hukukunda hak ehliyetinin kazanılması için gerekli olan status'lerin değişmesi, capitis deminutio sonucunu doğururdu. Gaius, üç̧ capitis deminutio durumunu birbirinden ayırird. Capitis deminutio maxima, özgürliik durumunun kaybedilerek köle durumuna gelinmesini; capitis deminutio media, yurttaşlık durumunun kaybedilerek Roma vatandaşlığından çıkılması ve yabancı olunmasını; capitis deminutio minima ise, aile babası egemenliği altına girilmesini ifade ederdi. ${ }^{37} \mathrm{Bir}$ kişinin capitis deminutio sonucunda, hak ehliyetini kaybetmesi durumunda, borçları da, eksik borç niteliği kazantrd, ${ }^{3 .}$

Iustinianus Dönemi'nde eksik borç ile insanın vicdanı sorumluluğu arasında bir bağlantı kurularak, diłğer soluti retentio durumlan da eksik borç kavramı altında toplanınca, bir takım yeni hukuki ilişkiler de bu sınıfa eklenmiş oldu. Böylece, vesayet altındaki küçüğüun, vasisinin auctoritası, olmadan yüklendiği borçlar; hukuk düzeni tarafından borç olarak kabul edilmeyen, ahlaki, sosyal ve dini nitelikteki bazı yükümlülüiklerin ifası: pactum ile yapılan faiz borçları; nafaka vermek zorunda olmayan kinselerin ödediłi nafakalar; kendisinin cihaz (dos) vermekle yükümlü olduğunu düşünen kadının verdiği cihaz, eski efendisine karşı yeminle borç altına girmemiş olan azatlının, kendisinin borçlu olduğunu düşünerek, patronus'una ifa ettiği şeyler, eksik borç olarak kabul edildi. Ancak bu çalışmalara rağmen, Iustinianus Dönemi'nde de, eksik borç başlığı altında toplanan hukuki ilişkilerin birbirlerine benzememesi, bu konuda tam olarak sistematik bir düzenleme yapılmasını engelledi. ${ }^{39}$

\footnotetext{
${ }^{36}$ RADO (Borçlar), s.235.

${ }^{37}$ BURDICK, W. L.: The Principles of Roman Law and Their Relation to Modem Law. Newyork 1938, s.214; KASER, M. (Çev.: DANNENBRING, R.): Roman Private Law, Durban 1965 , s.64.

${ }^{38}$ D. 4. 5, 2. 2 (ULPIANUS libro duodecimo ad edictum): 'Hi qui capite minumtur ex his. causis quae capitis deminutionem praecesserunt, manent obligati naturaliter.'

D. 4. 5. 2. 2: 'Kimde capitis deminutio meydana gelirse, o kimse bu sebeple. eksik borçla yükümlü olur.'

${ }^{39}$ DI MARZO, s.355-356.
} 